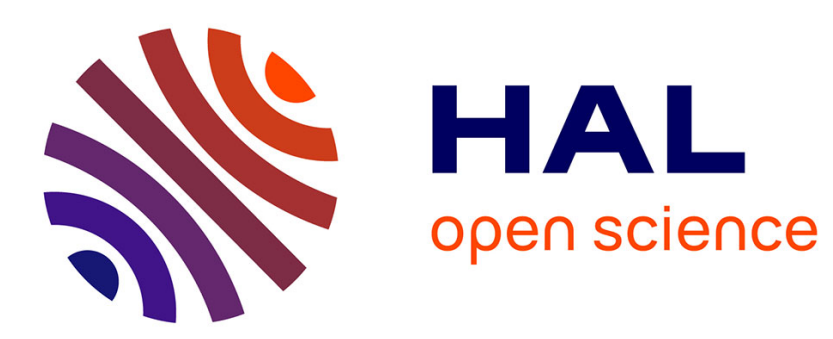

\title{
Growth of TiO2 thin films by AP-MOCVD on stainless steel substrates for photocatalytic applications
}

Florin-Daniel Duminica, Francis Maury, R. Hausbrand

\section{To cite this version:}

Florin-Daniel Duminica, Francis Maury, R. Hausbrand. Growth of TiO2 thin films by AP-MOCVD on stainless steel substrates for photocatalytic applications. Surface and Coatings Technology, 2007, vol. 201, pp. 9304-9308. 10.1016/j.surfcoat.2007.04.011 . hal-00806202

\section{HAL Id: hal-00806202 https://hal.science/hal-00806202}

Submitted on 29 Mar 2013

HAL is a multi-disciplinary open access archive for the deposit and dissemination of scientific research documents, whether they are published or not. The documents may come from teaching and research institutions in France or abroad, or from public or private research centers.
L'archive ouverte pluridisciplinaire HAL, est destinée au dépôt et à la diffusion de documents scientifiques de niveau recherche, publiés ou non, émanant des établissements d'enseignement et de recherche français ou étrangers, des laboratoires publics ou privés. 


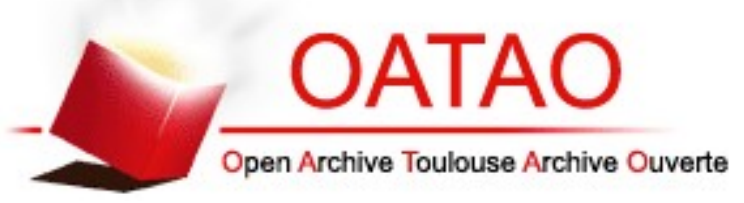

\section{Open Archive Toulouse Archive Ouverte (OATAO)}

OATAO is an open access repository that collects the work of Toulouse researchers and makes it freely available over the web where possible.

This is an author-deposited version published in: http://oatao.univ-toulouse.fr/ Eprints ID : 2442

To link to this article :

URL : http://dx.doi.org/10.1016/j.surfcoat.2007.04.011

To cite this version : Duminica, F.-D and Maury, Francis and Hausbrand, R. ( 2007) Growth of TiO2 thin films by AP-MOCVD on stainless steel substrates for photocatalytic applications. Surface and Coatings Technology, vol. 201 (n 22 23). pp. 9304-9308. ISSN 0257-8972

Any correspondence concerning this service should be sent to the repository administrator:staff-oatao@inp-toulouse.fr 


\title{
Growth of $\mathrm{TiO}_{2}$ thin films by AP-MOCVD on stainless steel substrates for photocatalytic applications
}

\author{
F.-D. Duminica ${ }^{\mathrm{a}, 1}$, F. Maury ${ }^{\mathrm{a}, *}$, R. Hausbrand ${ }^{\mathrm{b}}$ \\ ${ }^{\text {a }}$ CIRIMAT, CNRS/INPT/UPS, ENSIACET, 118 Route de Narbonne, 31077 Toulouse cedex 4, France \\ b Surface Functionalisation, ARCELOR Research Industry Gent, OCAS NV, John Kennedylaan 3, B-9060 Zelzate, Belgium
}

\begin{abstract}
$\mathrm{TiO}_{2}$ thin films were deposited under atmospheric pressure by MOCVD in the temperature range $400-600{ }^{\circ} \mathrm{C}$ on stainless steel and $\mathrm{Si}(100)$ substrates. Titanium tetraisopropoxide (TTIP) was used as Ti and O source. Single-phased anatase and bi-phased (anatase/rutile) coatings with controlled composition have been deposited depending on the temperature and the TTIP mole fraction. The films grown on stainless steel at low temperature $\left(<420^{\circ} \mathrm{C}\right)$ and low TTIP mole fraction $\left(<10^{-4}\right)$ are constituted of pure anatase and they exhibit a high photocatalytic activity under UV light and a high hydrophilicity. In the temperature range $430-600{ }^{\circ} \mathrm{C}$ the rutile starts growing leading to anatase/rutile mixtures and subsequently to a progressive decrease of both photocatalytic activity and wettability. Correlations between functional properties and microstructure of the films are discussed.
\end{abstract}

Keywords: MOCVD; $\mathrm{TiO}_{2}$; Photocatalysis; Wettability

\section{Introduction}

Water and air purification is the most promising application of photocatalysis since many organic pollutants are totally mineralized by this process. Anatase is one of the best photocatalysts [1]. It is self regenerating, recyclable and chemically stable. Many processes have been used for the deposition of $\mathrm{TiO}_{2}$ films including sol-gel [2], hydrothermal synthesis followed by dip-coating [3], spray-pyrolysis [4], pyrosol [5] and chemical vapor deposition [6-8]. Among them, atmospheric pressure metal organic chemical vapor deposition (AP-MOCVD) permits a good control of the deposition parameters and, subsequently, of the stoichiometry and microstructure of the films. It is a promising industrial process because no vacuum system is required and it is known for its good capability for large-scale production and continuous deposition. A great variety of substrates has been used as

\footnotetext{
* Corresponding author. Tel.: +33 562885669; fax: +33 562885600 .

E-mail address: francis.maury@ensicacet.fr (F. Maury).

${ }^{1}$ Present address: New Coating Technologies, ARCELOR Research Industry Liège, c/o Arcelor Research Liège SCRL, Rue Sompré 1, B.4400 Ivoz-Ramet, Belgium.
}

ceramics, polymers, glasses, silica microfibers [9] and metallic materials, particularly stainless steel [6-8]. The nature of the substrate influences the microstructure and the properties of the $\mathrm{TiO}_{2}$ films, as recently shown [10]. The knowledge of the role of the substrate is particularly important when very thin films have to be deposited.

This paper deals with the deposition of $\mathrm{TiO}_{2}$ by AP-MOCVD using TTIP on stainless steel (SS304L) and, for comparison, $\mathrm{Si}$ (100) substrates. It completes a parallel study published in the course of the review process of the present paper [10]. The deposition diagrams are determined for both substrates and the structural characteristics of the films are discussed in relation with their surface properties.

\section{Experimental}

A cold-wall vertical CVD quartz reactor was used for the deposition of the layers [7]. The substrates were placed on a stainless steel sample holder and the temperature $\left(350-650^{\circ} \mathrm{C}\right)$ was measured using a thermocouple. The gas streams were monitored using mass flow meters. The TTIP mole fraction was determined using a procedure described elsewhere [11]. The film microstructure was studied by X-ray diffraction (XRD) 

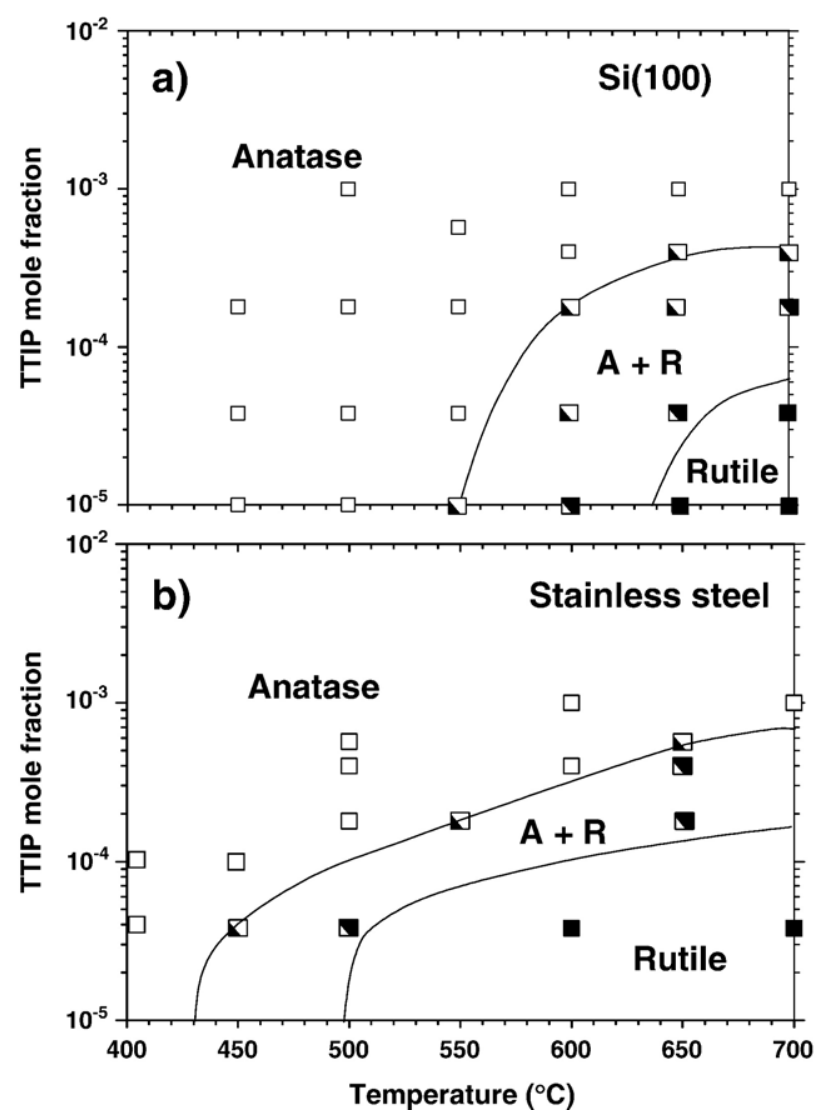

Fig. 1. XRD deposition diagram of anatase and rutile layers grown on (a) $\mathrm{Si}$ (100) and (b) SS304L as a function of deposition temperature and TTIP mole fraction. A mixed area limited by the solid lines separates the anatase and rutile domains.

using $\theta-\theta$ and grazing geometry $(\mathrm{Cu} \mathrm{K} \alpha)$. The surface morphology was observed using a scanning electron microscope (SEM) and the film thicknesses were determined on cross sections and confirmed by reflectance spectroscopy. SIMS depth profiles were carried out using $\mathrm{Cs}^{+}$sputtering.

The photocatalytic activity of $\mathrm{TiO}_{2}$ films was evaluated by measuring the decomposition rate of aqueous Orange $G$ solutions (10 ppm) using UV-VIS spectroscopy. The degradation reaction was carried out in a batch quartz photo-reactor placed in a thermostated chamber under the UV light of a lamp (HPLN Philips $125 \mathrm{~W}$ ) emitting at $365 \mathrm{~nm}$ chosen because absorption of Orange $\mathrm{G}$ is negligible at this wavelength. The solution was agitated with an inert Teflon magnetic stirrer. The surface area of the sample exposed to irradiation was $4 \mathrm{~cm}^{2}$ and the radiance was $1 \mathrm{~mW} / \mathrm{cm}^{2}$. The quantity of initial Orange $\mathrm{G}$ aqueous solution was $20 \mathrm{~cm}^{3}$. The direct photolysis of the solution (without photocatalyst) was found negligible for more than $24 \mathrm{~h}$.

The hydrophilicity was evaluated by measuring the contact angle of water droplets. Each value was an average of 3 measurements on different areas of the sample surface. The wettability measurements were realized on as-deposited samples after storage in dark for a week, without illumination on the sample before the test except the day light of the lab during the few minutes of the test.

\section{Results and discussion}

\subsection{Morphology and structure of the $\mathrm{TiO}_{2}$ films}

Typical growth conditions are reported elsewhere [7]. $\mathrm{TiO}_{2}$ films showed a good uniformity with different interferential colors depending on their thickness. The films grown at low temperature $\left(<450{ }^{\circ} \mathrm{C}\right)$ and low mole fraction $\left(10^{-5}-10^{-4}\right)$ exhibit a columnar structure and a relatively smooth surface morphology. By increasing the deposition temperature $\left(>550{ }^{\circ} \mathrm{C}\right)$ and the TTIP mole fraction in the range $10^{-3}$ $10^{-2}$, the morphology changes to a cauliflower-like structure and, as a result, the film porosity drastically increases leading to higher specific surface areas. Under these last conditions, a significant homogenous nucleation was observed in the reactor.

The $\mathrm{TiO}_{2}$ films exhibit a good crystallinity and are generally constituted of a mixture of anatase and rutile whose proportion depends on the growth conditions. On $\mathrm{Si}(100)$ and for low TTIP mole fractions, anatase is formed for temperatures lower than $550{ }^{\circ} \mathrm{C}$ then rutile starts growing leading to anatase/rutile mixtures until $650{ }^{\circ} \mathrm{C}$. Above this temperature pure rutile is obtained. The growth of rutile is favored on stainless steel substrates compared to $\mathrm{Si}(100)$ because the transition is shifted to lower temperatures (Fig. 1) in good agreement with recent observations [8]. Indeed, the rutile starts to form at $430{ }^{\circ} \mathrm{C}$ for a TTIP mole fraction of $10^{-5}$ to the detriment of anatase and its proportion increases with the temperature. Above $550{ }^{\circ} \mathrm{C}$ only the rutile phase is formed on SS304L. The rutile is generally deposited both at high temperature and low mole fraction of TTIP. Under these conditions the growth rate is not kinetically controlled and rutile is deposited because it is the most thermodynamically stable phase. By contrast, at low deposition temperature and/or using a high over saturation of the gas phase (high TTIP mole fraction) the growth of anatase is kinetically favored. The temperature range for the growth of anatase is broader on silicon than on steel substrate.

Fig. 2 shows the variation of anatase/rutile composition as a function of the thickness of $\mathrm{TiO}_{2}$ layers grown at $550{ }^{\circ} \mathrm{C}$ on stainless steel using a TTIP mole fraction of $1.8 \cdot 10^{-4}$. This

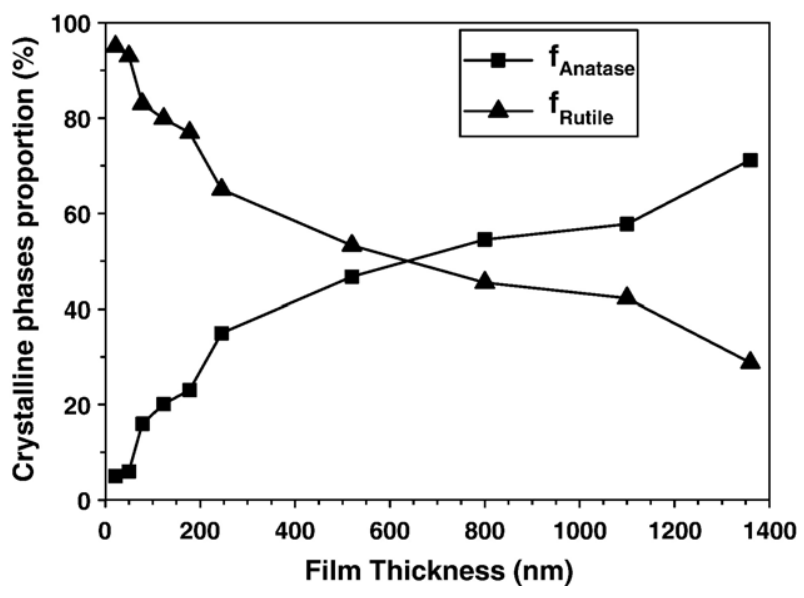

Fig. 2. Variation of anatase/rutile proportion as a function of the thickness of $\mathrm{TiO}_{2}$ layers grown at $550{ }^{\circ} \mathrm{C}$ on SS304L using a TTIP mole fraction of $1.8 \cdot 10^{-4}$. 


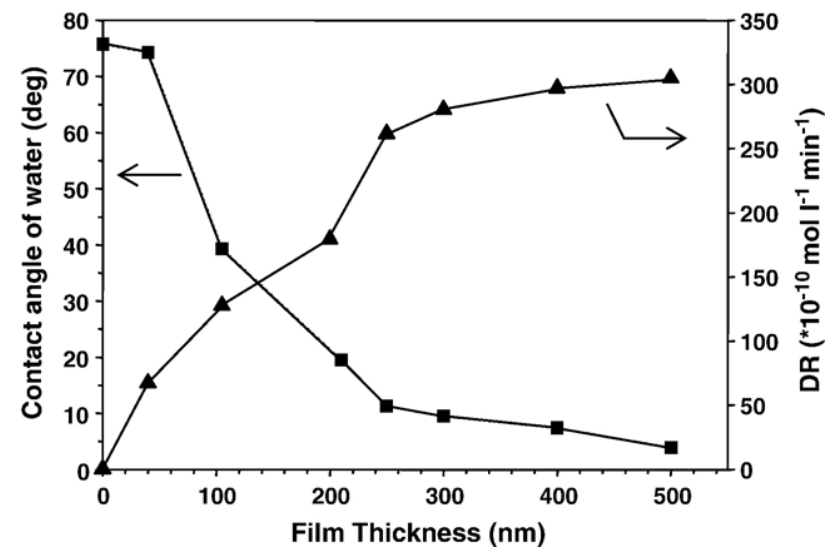

Fig. 3. Influence of the $\mathrm{TiO}_{2}$ film thickness on (a) the contact angle of water without UV irradiation (RH 30\%) and (b) the photocatalytic decomposition rate (DR) of Orange G solutions (10 ppm) under UV irradiation (365 nm). The films were grown on stainless steel at $400{ }^{\circ} \mathrm{C}$ using TTIP mole fraction $10^{-4}$.

composition was determined by XRD from the intensity of the strongest anatase (101) and rutile (110) peaks [12]. Almost pure rutile phase was deposited for thicknesses lower than $100 \mathrm{~nm}$, while anatase/rutile mixture is observed for thicknesses higher than $200 \mathrm{~nm}$. The rutile nucleation is favored by the SS304L surface likely due to diffusion of ions from the steel substrate. When the surface is completely covered and after a critical $\mathrm{TiO}_{2}$ thickness, nucleation and growth of anatase occurs. Increasing the thickness, anatase grows faster than rutile and gradually covers the rutile underlayer.

This let us assume a diffusion of cations as $\mathrm{Cr}^{3+}$ and $\mathrm{Fe}^{3+}$ originating from the passive oxide layer of SS304L into the $\mathrm{TiO}_{2}$ film. Indeed, the low deposition rate and long deposition time favor interdiffusion between $\mathrm{TiO}_{2}$ and ions from the substrate. SIMS depth profiles of a $100 \mathrm{~nm}$ thick rutile $\mathrm{TiO}_{2}$ film grown on SS304L at $500{ }^{\circ} \mathrm{C}$ using TTIP mole fraction of $10^{-4}$ (not shown) have revealed a $\mathrm{Cr}$ and $\mathrm{Fe}$ rich intermediate layer at the interface between $\mathrm{TiO}_{2}$ and the substrate apparently thicker than the ca. $20 \mathrm{~nm}$ of the passive layer of SS304L. No evidence for chromium or iron oxides as additional phases was found by XRD. Relatively high diffusion of iron during the calcinations at $400{ }^{\circ} \mathrm{C}$ of $\mathrm{TiO}_{2}$ deposited on stainless steel webnet was previously reported [13] and all the more extensive at $700{ }^{\circ} \mathrm{C}$ [14]. Here, the temperature is only $500^{\circ} \mathrm{C}$ but cations diffusion is still present and it enhances the rutile nucleation and growth. This is in good agreement with a parallel recent work [10].

The anatase-rutile transformation involves an overall contraction of the oxygen network structure (about 8\%) followed by a cooperative rearrangement of $\mathrm{Ti}^{4+}$ and $\mathrm{O}^{2-}$ ions. This shrinkage takes place by a distortion of the oxygen network and a shift of the majority of the $\mathrm{Ti}^{4+}$ ions by breaking two of the six Ti-O anatase bonds to form the new Ti-O bonds of the rutile structure. It has been proposed that the removal of oxygen ions, which generates lattice vacancies, accelerates the transformation and inhibits the formation of interstitial titanium. The enhancement or inhibiting effect of additives is dependent on their ability to enter the $\mathrm{TiO}_{2}$ lattice thereby creating $\mathrm{O}$ vacancies or interstitial $\mathrm{Ti}^{3+}$ ions, respectively. For instance, it was found that $1.0 \mathrm{~mol} \% \mathrm{NiO}, \mathrm{CoO}, \mathrm{MnO}_{2}, \mathrm{Fe}_{2} \mathrm{O}_{3}$, or $\mathrm{CuO}$ promotes anatase-to-rutile transformation [15] as well as the presence of $\mathrm{Fe}^{3+}$ ions [16]. The formation of an amorphous $\mathrm{SiO}_{2}$ surface layer was considered to be important in retarding the anatase-to-rutile phase transition by suppressing diffusion between anatase particles in direct contact and limiting their ability to act as surface nucleation sites for rutile [17]. This was confirmed recently [10]. Similar effects were observed by adding $\gamma-\mathrm{Al}_{2} \mathrm{O}_{3}[18]$.

\subsection{Surface properties of $\mathrm{TiO}_{2}$ films}

Fig. 3 shows the decomposition rate of Orange G solutions under UV irradiation by $\mathrm{TiO}_{2}$ layers grown on $\mathrm{SS} 304 \mathrm{~L}$ as a function of the thickness. The decomposition rate or photocatalytic activity has been evaluated from the slope of the relative variation of concentration of the orange $G$ solution versus the time (quasi linear decrease for the first $3 \mathrm{~h}$ ). It increases strongly with $\mathrm{TiO}_{2}$ thickness until approx. $300 \mathrm{~nm}$. For thicknesses higher than $300 \mathrm{~nm}$, the decomposition rate increases very slowly and it tends toward a plateau. A similar behavior with a maximum photocatalytic activity for a $\mathrm{TiO}_{2}$ thickness around $250 \mathrm{~nm}$ was previously reported [13]. When the film is dense and too thick, most of the electron-hole pairs are generated too deeply in the bulk of $\mathrm{TiO}_{2}$ and they never reach the surface. Conversely, if the film is too thin, only a small part of the incident light is absorbed by the $\mathrm{TiO}_{2}$ film and the photocatalysis is low.

Interestingly, the variation of the water contact angle with $\mathrm{TiO}_{2}$ thickness (without UV exposure) is opposite (Fig. 3). The contact angle decreases gradually by increasing the $\mathrm{TiO}_{2}$ thickness from $76^{\circ}$ (substrate) to less than $9^{\circ}$ for films thicker than $300 \mathrm{~nm}$. Obviously, in the case of the present films, the critical thickness necessary to obtain super-hydrophilic films seems to be the same than the one found for a maximum photocatalytic activity. The wettability of solid surfaces with liquids is governed by chemical and electronic properties of the surfaces and their roughness. Therefore, the control of the film

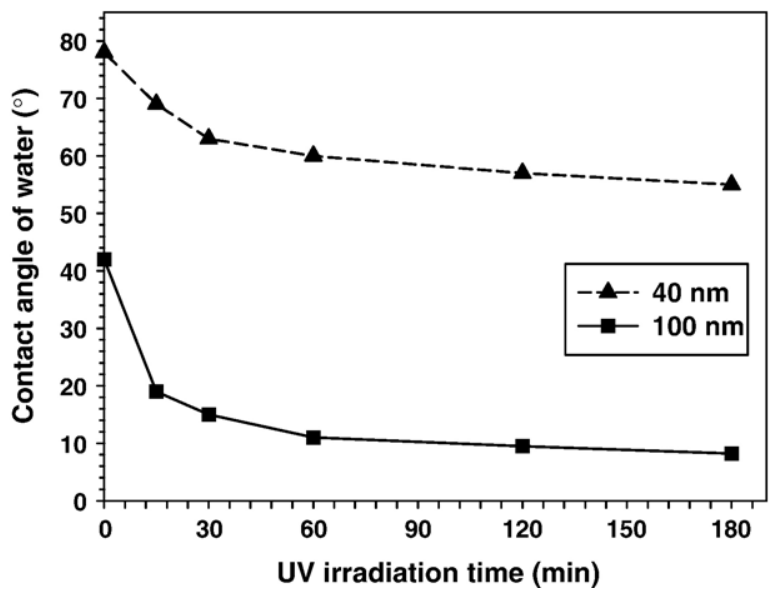

Fig. 4. Variation of the contact angle of water with the UV irradiation time for two $\mathrm{TiO}_{2}$ films (40 and $100 \mathrm{~nm}$ ) grown on SS304L at $400{ }^{\circ} \mathrm{C}$ using TTIP mole fraction $10^{-4}$ (relative humidity RH $30 \%$ ). 
microstructure (porosity, crystallite size) is a way to improve the hydrophilic behavior.

Fig. 4 shows the variation of the contact angle of water with the irradiation time for two very thin $\mathrm{TiO}_{2}$ films (40 and $100 \mathrm{~nm}$ ) grown on stainless steel at $400{ }^{\circ} \mathrm{C}$ using TTIP mole fraction $10^{-4}$. For instance, the contact angle decreases from ca. $42^{\circ}$ to $10^{\circ}$ after an UV exposure for few tens of minutes. The hydrophilic/hydrophobic switching on $\mathrm{TiO}_{2}$ surfaces was previously attributed to the formation and removal of surface hydroxyl groups. UV irradiation causes the reduction of $\mathrm{Ti}^{4+}$ to $\mathrm{Ti}^{3+}$ and the production of $\mathrm{O}$ vacancies on $\mathrm{TiO}_{2}$ surfaces. Subsequently, dissociative adsorption of ambient water vapor on these $\mathrm{O}$ vacancies results in the formation of surface hydroxyl groups (hydrophobic to hydrophilic transition).

Fig. 5 shows the effect of the deposition temperature on the decomposition rate of Orange $\mathrm{G}$ solutions by $\mathrm{TiO}_{2}$ films grown on stainless steel. The thickness of the $\mathrm{TiO}_{2}$ layer was fixed at $300 \mathrm{~nm}$ and the TTIP mole fraction was $10^{-4}$. The photocatalytic activity of these layers decreases rapidly from $28 \mathrm{nmol} \mathrm{l}^{-1} \mathrm{~min}^{-1}$ at $400{ }^{\circ} \mathrm{C}$ to $8 \mathrm{nmol}^{-1} \mathrm{~min}^{-1}$ at $600^{\circ} \mathrm{C}$. At $400{ }^{\circ} \mathrm{C}$ only anatase is deposited, while at $600{ }^{\circ} \mathrm{C}$ pure rutile is deposited. The progressive decrease of the photocatalytic activity is likely due to the increase of rutile amount (Fig. 1). Furthermore, the temperature increase leads to a higher diffusion of cationic impurities from the substrate which can also affect the photocatalytic efficiency by increasing the recombination process of photo-electronic carriers [19].

Fig. 6 shows the variation of the surface roughness (Ra) and of the contact angle of water for $\mathrm{TiO}_{2}$ films grown on $\mathrm{Si}(100)$ and SS304L in the temperature range $400-600{ }^{\circ} \mathrm{C}$ using TTIP mole fraction $10^{-4}$. For $\mathrm{Si}(100)$ the contact angle is almost constant (12-18 deg) for the films grown in the temperature range $400-550{ }^{\circ} \mathrm{C}$ while $\mathrm{Ra}$ increases more significantly for $T>500^{\circ} \mathrm{C}$. Above $550{ }^{\circ} \mathrm{C}$, the highest values of Ra are probably due to a contribution of homogenous nucleation and the formation of rutile. The contact angle seems to be more strongly correlated to the roughness of the film on SS304L (Fig. 6). A continuous increase is observed for both curves by increasing

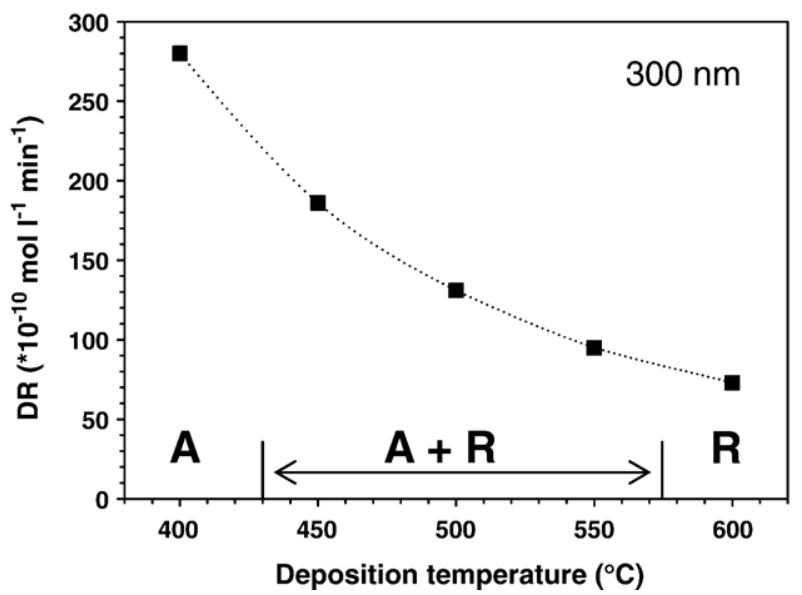

Fig. 5. Photocatalytic decomposition rate of Orange G solutions (10 ppm) under UV irradiation $\left(365 \mathrm{~nm}\right.$ ) of $\mathrm{TiO}_{2}$ films (300 nm thick) grown on SS304L at various deposition temperatures using TTIP mole fraction $10^{-4}$.
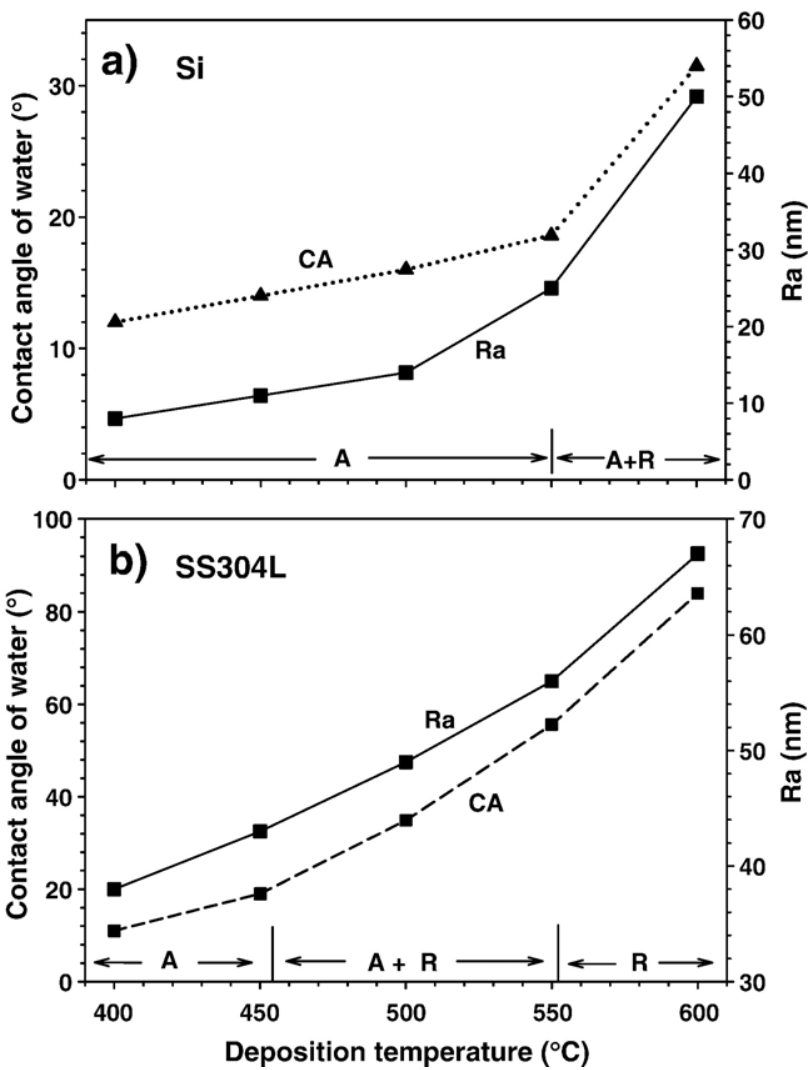

Fig. 6. Variation of the contact angle of water (CA) and roughness (Ra) for $\mathrm{TiO}_{2}$ films grown on (a) $\mathrm{Si}(100)$ and (b) stainless steel at various temperatures (TTIP mole fraction $10^{-4}$ ).

the temperature leading to hydrophobic surfaces at $600{ }^{\circ} \mathrm{C}$. A good correlation is also observed with the photocatalytic decay (Fig. 5) when the deposition temperature increases. The higher the rutile proportion, the lower the photocatalytic efficiency. Because diffusion is faster at high temperature, cationic impurities from the substrate may also explain the photocatalytic decay of films grown at high temperature.

\section{Conclusions}

$\mathrm{TiO}_{2}$ coatings were deposited by AP-MOCVD on stainless steel coupons and $\mathrm{Si}(100)$ wafers for comparison. Their morphology and structure can be controlled by changing the key parameters of the process, i.e. the growth temperature and the TTIP mole fraction. These results permit the determination of deposition diagrams showing that the films grown on SS304L at low temperature $\left(<420^{\circ} \mathrm{C}\right)$ and low TTIP mole fraction are only constituted of anatase. They exhibit a relatively high photocatalytic activity under UV light and a high hydrophilicity even without UV irradiation. The photocatalytic activity increases strongly with the thickness of anatase layer then more slowly for thicknesses higher than the critical value of $300 \mathrm{~nm}$. In the temperature range $430-600{ }^{\circ} \mathrm{C}$ the rutile starts growing on SS304L leading to a progressive decrease of the UV photocatalytic activity and of hydrophilicity.

Because rutile nucleation is favored by cationic species from the steel surface and because anatase and rutile have different 
growth rates under fixed conditions, the structure of $\mathrm{TiO}_{2}$ APCVD films on SS304L depends strongly both on the deposition temperature and TTIP mole fraction. An increase of the deposition temperature facilitates the growth of rutile while the formation of anatase is favored by high mole fractions. Thus, even at relatively high temperature (600$650{ }^{\circ} \mathrm{C}$ ) only anatase can be deposited using high mole fractions. An increase of the temperature is important in order to reach the high growth rates required for continuous deposition of anatase. The control of the interface between the steel substrate and the film is very important for films thinner than $100 \mathrm{~nm}$. To avoid the harmful diffusion of substrate ions into $\mathrm{TiO}_{2}$ during the APCVD process, a low thermal budget is required which is achieved using a high growth rate of anatase. The growth of a barrier layer on the substrate prior to $\mathrm{TiO}_{2}$ deposition is also a potential solution [10,17]. Nitrogen doping of these AP-MOCVD $\mathrm{TiO}_{2}$ layers can be achieved to get photocatalytic activity in the visible range [20].

\section{References}

[1] A.L. Linsebigler, G. Lu, J.T. Yates, Chem. Rev. 95 (1995) 735.

[2] K. Kato, A. Tsuzuki, Y. Torii, H. Taoda, T. Kato, Y. Butsugan, J. Mater. Sci. 30 (1995) 837.

[3] M. Langlet, A. Kim, M. Audier, C. Guillard, J.M. Herrmann, J. Mater. Sci. 38 (2003) 3945.
[4] M. Okuya, N.A. Prokudina, K. Mushika, S. Kaneko, J. Electrochem. Soc. 19 (1999) 903

[5] F.-D. Duminica, F. Maury, S. Abisset, Thin Solid Films (2007), doi:10.1016/j.tsf.2007.03.057.

[6] G.A. Battiston, R. Gerbasi, M. Porchia, L. Rizzo, Chem. Vap. Depos. 5 (1999) 73.

[7] F.-D. Duminica, F. Maury, F. Senocq, Surf. Coat. Technol. 188-189 (2004) 255.

[8] P. Evans, M.E. Pemble, D. Sheel, Chem. Mater 18 (2006) 5750.

[9] C. Sarantopoulos, A. N. Gleizes, F. Maury, Surf. Coat. Technol., Proceeding EUROCVD 16, (2007-this issue). doi:10.1016/j.surfcoat.2007.04.073.

[10] P. Evans, T. English, D. Hammond, M.E. Pemble, D.W. Sheel, Appl. Catal., A Gen. 321 (2007) 140.

[11] F.-D. Duminica, F. Maury and F. Senocq, Chem. Vap. Deposition, submitted for publication.

[12] R. Jenkins, R.L. Snyder, Chemical Analysis, Introduction to X-ray Powder Diffractometry, vol. 138, John Wiley \& Sons, New York, 1996, p. 403.

[13] J. Shang, W. Li, Y. Zhu, J. Mol. Catal., A Chem. 202 (2003) 187.

[14] J.-M. Herrmann, H. Tahiri, C. Guillard, P. Pichat, Catal. Today 54 (1999) 131.

[15] Y. Iida, S. Ozaki, J. Am. Ceram. Soc. 44 (1961) 120.

[16] A. Navio, M. Macias, M. Gonzales-Catalan, A. Justo, J. Mater. Sci. 27 (1992) 3036.

[17] K. Okada, N. Yamamoto, Y. Kameshima, A. Yasumori, K.J.D. MacKenzie, J. Am. Ceram. Soc. 84 (2001) 1591.

[18] H. Zhang, J.F. Banfield, J. Mater. Res. 15 (2000) 437.

[19] A. Fernandez, G. Lassaletta, V.M. Jimenez, A. Justo, A.R. Gonzalez-Elipe, J.-M. Herrmann, H. Tahiri, Y. Ait-Ichou, Appl. Catal., B Environ. 7 (1995) 49.

[20] F.-D. Duminica, F. Maury, R. Hausbrand, Surf. Coat. Technol., Proceeding EUROCVD 16, (2007-this issue). doi:10.1016/j.surfcoat.2007.04.061. 